\title{
SABERES NECESSÁRIOS AO PROFESSOR PARA AVALIAR A APRENDIZAGEM DE CRIANÇAS NA SALA DE AULA DE LÍNGUAS ESTRANGEIRAS
}

\author{
Juliana Reichert Assunção Tonelli* \\ Gladys Quevedo-Camargo**
}

\begin{abstract}
RESUMO: Nas últimas décadas, tem havido um crescimento significativo do ensino de línguas estrangeiras para crianças no Brasil, em especial da língua inglesa. Considerando o letramento em avaliação um elemento essencial no ensino e na aprendizagem, neste artigo discutimos o letramento em avaliação do professor nesse campo do conhecimento. Os dados foram gerados por meio de um questionário, o qual foi respondido por 151 professores de todo o país. O questionário original consiste de 70 assertivas acerca de uma ampla variedade de assuntos relacionados a avaliação da aprendizagem de línguas estrangeiras por crianças. Para esse artigo, o qual objetiva apresentar um recorte de uma pesquisa mais ampla sobre letramento em avaliação, selecionamos quatro afirmativas as quais, do nosso ponto de vista, são conhecimentos cruciais para o trabalho docente e para a integração do ensino, aprendizagem e avaliação: 1. saber utilizar avaliações para guiar os objetivos do ensino ou da aprendizagem; 2. saber utilizar as avaliações para avaliar o progresso na aprendizagem de línguas; 3 . saber utilizar as avaliações para diagnosticar os pontos fortes e fracos dos alunos; e 4. saber utilizar as avaliações para motivar a aprendizagem dos alunos. Os resultados mostraram que a grande maioria dos participantes considera que não sabem ou sabem pouco sobre os quatro assuntos, o que indica a necessidade urgente de oferecer formação inicial ou continuada para aqueles que ensinam LEC no Brasil.
\end{abstract}

PALAVRAS-CHAVE: Conhecimentos essenciais do professor; Ensino de línguas estrangeiras para crianças; Letramento em avaliação de línguas.

\footnotetext{
* Doutora em Estudos da Linguagem pela Universidade Estadual de Londrina (Uel). Professora Adjunta da Universidade Estadual de Londrina.

** Doutora em Estudos da Linguagem pela Universidade Estadual de Londrina (Uel). Professora adjunta do Departamento de Línguas Estrangeiras e Tradução (LET) e coordenadora do Programa de Pós-graduação em Linguística Aplicada (PGLA) da Universidade de Brasília (UnB).
} 


\section{Introdução}

A crescente oferta de aulas de línguas estrangeiras (LE) nas séries iniciais de escolarização (Educação Infantil e Ensino Fundamental 1) confere urgência às pesquisas que, de alguma forma, se ocupam de questões diretamente relacionadas ao ensino, à aprendizagem e à formação de professores para atuar no contexto de línguas estrangeiras para crianças (LEC) no Brasil (TONELLI, FERREIRA e BELO-CORDEIRO, 2017). Nesse sentido, Tonelli e Pádua (2017) mostram que a recorrência de temáticas pesquisadas no Brasil aponta para o fato de que o aumento da oferta de LEC nas séries iniciais vem acarretando a necessidade de formação de professores para atuar também em contextos específicos, como a sala de aula de crianças aprendendo línguas (ROCHA e BASSO, 2007; TONELLI, 2016, por exemplo).

No Brasil, nos últimos anos, o ensino de língua inglesa para crianças (LIC) tem sido implantado tanto em contextos de ensino privado (SANTOS, 2005, 2009; TONELLI, 2005; MONTEIRO, 2016; MONTES, 2017; SELBACH e SARMENTO, 2017) como em ensino público (DIAS, 2014; DIAS e BROSSI, 2015; TUTIDA, 2016; COLOMBO e CONSOLO, 2017; MELLO, 2017; ANDRADE e CONCEIÇÃO, 2017; BUOSE e SANTOS, 2017). Apesar de sua não obrigatoriedade nos anos iniciais do EF1 público brasileiro, a língua inglesa no EFI público já é uma realidade seja em forma de projetos e/ou como disciplina da grade curricular, conforme nos mostra Tanaca (2017).

Independente do contexto e de sua organização, o fato é que professores/as que se enveredam por esses caminhos enfrentam desafios, tais como o despreparo para lidar com esse público específico, a falta de políticas públicas e diretrizes orientadoras do ensino, a carência de cursos de formação docente, a falta de material didático, dentre outros.

Inerente ao processo de ensino e aprendizagem está a avaliação da aprendizagem. Não se pode desconsiderar sua existência, tampouco sua importância para o processo de ensino e de aprendizagem, pois coexistem. No entanto, pesquisas revelam a falta de letramento em avaliação do professor de língua estrangeira (QUEVEDO-CAMARGO, 2018), incluindo o de LEC (TONELLI e QUEVEDO-CAMARGO, 2018). 
Considerando essa lacuna na formação de professores que atuam ensinando línguas para crianças, o objetivo deste artigo é apresentar um recorte de uma pesquisa ${ }^{1}$ feita com 151 professores de inglês e espanhol de todo o Brasil sobre saber avaliar. Nesse recorte, destacamos quatro saberes que, no nosso entendimento, são essenciais para que o professor desenvolva seu trabalho integrando ensino-aprendizagem-avaliação: 1. saber utilizar avaliações para guiar os objetivos do ensino ou da aprendizagem; 2. saber utilizar as avaliações para avaliar o progresso na aprendizagem de línguas; 3. saber utilizar as avaliações para diagnosticar os pontos fortes e fracos dos alunos; e 4. saber utilizar as avaliações para motivar a aprendizagem dos alunos.

Este artigo organiza-se da seguinte forma: na próxima parte, discorremos brevemente sobre o conceito de letramento em avaliação de línguas, o qual embasa todo o trabalho desenvolvido por nós tanto de pesquisa quanto de formação de professores. Em seguida, apresentaremos brevemente as questões metodológicas da pesquisa completa que deu origem a este recorte e, na sequência, discorreremos sobre os quatro saberes com os dados obtidos e algumas reflexões. Encerraremos com nossas reflexões gerais sobre o letramento em avaliação de professores de línguas para crianças e com sugestões de encaminhamentos.

\section{O conceito de letramento em avaliação de línguas}

Uma das atividades inerentes ao trabalho de todo professor é a avaliação o que demanda formação docente específica (SCARAMUCCI, 2006) e implica o desenvolvimento de letramento para avaliar, incluindo o contexto de avaliação de LIC (MCKAY, 2006; NIKOLOV, 2016; TSAGARI E IOANNOU-GEORGIOU, 2017).

\footnotetext{
${ }^{1}$ Este artigo é um recorte de uma pesquisa mais ampla desenvolvida em nível pós-doutoral pela primeira autora sob a supervisão da segunda no Programa de Linguística Aplicada na Universidade de Brasília em 2018. A pesquisa foi aprovada pelo Comitê de Ética envolvendo Seres Humanos (CAE 07609319.4.0000.5231).
} 
De acordo com Mosquera e Macías (2014), a avaliação possui um papel central no processo de ensino e aprendizagem não somente em língua inglesa, mas em todos os campos do conhecimento. Para eles, a avaliação é, juntamente com professores, alunos, recursos e contexto, um dos cinco componentes que contribuem para determinar a qualidade do ensino.

No conceber dos mesmos autores, boas práticas avaliativas podem beneficiar tanto alunos quanto professores de várias formas: auxiliam professores a identificar se um determinado conteúdo ou o ritmo da aula é ou não adequado; ajudam os professores a monitorar a aprendizagem dos alunos ao longo do curso; auxiliam os alunos a identificar o próprio progresso e fortalecem a autoconfiança dos aprendizes.

Contudo, conforme Mosquera e Macías (2014), espera-se que os professores conheçam e saibam trabalhar com todos os aspectos da avaliação para dar suporte às suas práticas de sala de aula e corresponder às necessidades dos alunos, dos pais e da comunidade escolar. Em outras palavras, espera-se que os professores tenham letramento em avaliação.

De acordo com Stiggins (2002) e Popham (2004), o conceito se refere a uma compreensão dos princípios que regem uma avaliação sólida, bem informada e justa. Implícita nessa definição, está a necessidade de os professores possuírem conhecimentos e entendimento adequados para avaliar seus alunos de forma a maximizar o processo de ensino e aprendizagem (COOMBE et al., 2012).

Para Stiggins (1995; 2002), uma avaliação sólida, bem informada e justa caracterizase por: 1. originar-se de, e servir a, propósitos claros; 2. originar-se de, e refletir, objetivos de rendimento claros e apropriados; 3 . basear-se em um método avaliativo adequado (ao propósito e aos objetivos); 4. retratar adequadamente o rendimento dos alunos; e 5. exercer controle sobre todas as fontes relevantes de viés e distorções. Portanto, um professor letrado em termos de avaliação trabalha sabendo o que e por quê está avaliando; qual a melhor forma de avaliar determinado aspecto do processo de ensino e aprendizagem; como gerar 
dados confiáveis do desempenho do aluno; o que pode dar errado; e como prevenir possíveis problemas na e decorrente da avaliação.

Fulcher (2012, p. 125) apresenta-nos uma definição mais abrangente de letramento em avaliação de línguas:

Os conhecimentos, as capacidades e habilidades necessárias para elaborar, desenvolver, manter ou analisar, exames padronizados de larga escala ou testes usados em sala de aula, a familiaridade com os processos avaliativos, e a consciência dos princípios e conceitos que orientam e subjazem a prática, incluindo questões éticas e códigos de conduta. A habilidade de situar os conhecimentos, as capacidades, os processos, os princípios e os conceitos em contextos históricos, sociais, políticos e filosóficos mais amplos a fim de compreender por que determinadas práticas surgiram, e como analisar o papel e o impacto da avaliação na sociedade, nas instituições, e nos indivíduos. (FULCHER, 2012, v. 2: p. 125: tradução nossa) ${ }^{2}$.

Neste trabalho, buscamos situar nossas reflexões no contexto da avaliação de LEC e/ou LIC a partir da constatação de que a literatura nos mostra que esse público tem necessidades diferentes dos aprendizes mais velhos, pois embora em qualquer faixa etária o aluno precise de algum tipo de retorno do professor (no sentido de devolutiva com relação aos seus pontos fortes e fracos), as crianças, em geral, necessitam de mais ajuda e apoio para compreender o quê e como podem ou precisam aprender. Além disso, é necessário mantê-las interessadas na atividade sendo desenvolvida, uma vez que para essa faixa etária, há maior probabilidade de sentirem-se desmotivadas diante de algum feedback adverso ou de algum insucesso na realização de atividades, sejam elas avaliativas ou não (HASSELGREEN, 2012).

\footnotetext{
${ }^{2}$ No original: "The knowledge, skills and abilities required to design, develop, maintain or evaluate, large-scale standardized and/or classroom based tests, familiarity with test processes, and awareness of principles and concepts that guide and underpin practice, including ethics and codes of practice. The ability to place knowledge, skills, processes, principles and concepts within wider historical, social, political and philosophical frameworks in order understand why practices have arisen as they have, and to evaluate the role and impact of testing on society, institutions, and individuals."
} 
Conforme Malloy (2015), algumas características próprias às crianças podem trazer implicações para a avaliação da aprendizagem de línguas naquela faixa etária: crianças reagem de maneiras diferentes à situações de estresse, possuem uma concepção diferente de tempo e sequência de fatos, precisam saber por que estão realizando uma determinada tarefa, estão em processo de aquisição e de aprendizagem da língua materna, compreendem mais do que produzem e se distraem com mais facilidade do que aprendizes mais velhos. Essas e outras características inerentes aos pequenos aprendizes precisam ser consideradas não somente no momento da atividade avaliativa em si, mas também aos que antecedem à atividade avaliativa, como por exemplo, traçar os objetivos de ensino desde o início do processo.

Para Hasselgreen (2012), avaliar crianças aprendendo línguas estrangeiras é um trabalho gratificante e especial, mas apresenta muitos desafios. Para a autora, envolve o conhecimento das características do público-alvo, as quais determinarão tanto o tipo de tarefas por meio das quais esse público apresentará melhor desempenho, quanto o tipo de retorno a ser oferecido para a progressão da aprendizagem. Envolve também as habilidades linguísticas que se espera que as crianças desenvolvam, bem como os propósitos específicos da aprendizagem em cada faixa etária.

Há, portanto, muito a ser investigado sobre o que o professor de línguas estrangeiras para crianças no Brasil precisa saber para desenvolver seu trabalho de forma mais bem informada e satisfatória. Nossa contribuição para tal investigação é apresentada na próxima seção, onde explicamos brevemente a metodologia adotada para a pesquisa e para o recorte aqui apresentado.

\section{As questões metodológicas da pesquisa}

Para atingirmos o objetivo a que nos propusemos, aplicamos um questionário online utilizando o GoogleForms ${ }^{3}$, em formato de escala Likert, o qual foi adaptado da Language

${ }^{3}$ Ferramenta digital gratuíta que cria formulários online. 
Assessment Literacy Survey ${ }^{4}$, elaborada por Kremmel e Harding (LANCASTER UNIVERSITY, no prelo). Essa survey, que chamamos de questionário, é composta por seis perguntas sobre o perfil do respondente e de 70 assertivas, organizadas em sete blocos, as quais versam sobre diferentes temas ligados à avaliação no contexto investigado ${ }^{5}$. Esse questionário foi traduzido e adaptado para o contexto brasileiro por nós.

O link de acesso ao questionário foi enviado a alunos de um curso de pós-graduação lato sensu em Ensino de Inglês para Crianças da Universidade Estadual de Londrina, na modalidade EAD e, aos participantes inscritos em um evento bianual sediado na mesma Universidade voltado à formação de professores de LEC 6 . Assim, de um total de 313 contatos, obtivemos 151 respostas de professores de várias partes do país, as quais foram analisadas a partir da tabulação feita pelo próprio GoogleForms.

Importante dizer que reconhecemos alguns fatores que podem, em certa medida, limitar a confiabilidade 7 das respostas obtidas. O primeiro deles é o fato de que todo questionário fechado restringe, de certo modo, as possibilidades de resposta. Diferentemente de uma entrevista, por exemplo, o questionário pode ser um instrumento mais impessoal e oferecer pouco espaço para a reflexão. Ponderamos ainda que, para responder a algumas assertivas, os professores podem ter tido uma visão limitada ou até mesmo equivocada de seu grau de letramento em avaliação de línguas ${ }^{8}$ ou ainda dificuldade em avaliar-se. Por

${ }^{4}$ http://wp.lancs.ac.uk/ltrg/projects/language-assessment-literacy-survey/

${ }^{5}$ Ressaltamos que no questionário online foi incluído também o Termo de Consentimento Livre Esclarecido no qual o/a respondente declarou ter lido e concordar com as informações contidas na seção "Apresentação ao participante", estar ciente da finalidade do presente questionário e aceitar participar da pesquisa.

${ }^{6}$ Trata-se do Encontro de II Professores de Inglês para Crianças e do I Seminário de Avaliação em Língua Estrangeira para Crianças que, no ano de 2019, encontra-se em sua quarta edição. Por ser um evento de âmbito nacional, os respondentes são professores de várias partes do Brasil.

7 A confiabilidade de um instrumento avaliativo pode ser compreendida como sendo a consistência dos resultados que o indivíduo obtém independente do momento ou das circunstâncias que ela é avaliada (SCARAMUCCI, 2009; TOFOLLI et al, 2016). Para Cameron (2001), a confiabilidade indica o quanto um teste ou avaliação atinge o que se propõe.

${ }^{8}$ Agradecemos a Profa. Matilde Scaramucci (UNICAMP) pelas ricas observações na análise do questionário, por ocasião de nossa participação (TONELLI e QUEVEDO-CAMARGO, 2018) no 66. Seminário do GEL na Unesp em São José do Rio Preto/SP. 
exemplo, o respondente pode considerar que determinada conduta sua não seja adequada ou ainda que, em sua perspectiva, não saiba como lidar com determinado aspecto da avaliação, mas pode ser que sua prática docente revele o oposto, ou vice-versa.

$\mathrm{Na}$ próxima seção, apresentamos os dados gerais dos 151 professores que responderam ao nosso questionário. Em seguida, discorremos sobre as respostas fornecidas a quatro das 70 assertivas respondidas pelos participantes, que foram selecionadas pela sua relação direta com a prática da avaliação em sala de aula.

\section{Discussão e análise dos dados}

\section{Dados gerais dos professores}

Do total de 151 respondentes - 88, 1\% declarou-se ser sexo feminino; 11,3\% do sexo masculino e $0,06 \%$ preferiu omitir essa informação. Sobre a faixa etária dos participantes, esta variou de 21 a 53 anos e, no que se refere ao tempo de experiência como professor de línguas estrangeiras para crianças, esta variou de 6 meses a 30 anos.

Quanto à experiência profissional dos 151 respondentes, embora o questionário tenha sido direcionado a um público específico - professores em formação inicial e/ou continuada com vivência no ensino de línguas estrangeiras para crianças - alguns $(24,5 \%)$ afirmaram não terem tido contato algum com o ensino de línguas estrangeiras para a faixa etária investigada.

Diante da pergunta Você atua como professor/ a no ensino de linguas estrangeiras para crianças de 0 a 12 anos?, 75,5\% afirmaram atuar no contexto investigado e 24, 5\% disseram que não.

Com relação à pergunta Quanto à sua experiência profissional como professor de línguas para crianças, como você se classifica?, obtivemos as seguintes respostas:

Quadro 1: experiência profissional dos respondentes

\begin{tabular}{c|c|c} 
NOVATO & EXPERIENTE & MUITO EXPERIENTE \\
\hline $51 \%$ & $43,7 \%$ & $5,3 \%$
\end{tabular}

Fonte: as autoras. 
Tal resultado importa na medida em que se pode traçar um paralelo entre a experiência profissional dos participantes, as respostas obtidas e o tempo de experiência dos respondentes. Embora o percentual de professores novatos seja maior que os que se consideram experientes, por meio das respostas apresentadas observamos que, mesmo dentre os 43,7\% (experientes), muitos indicaram não saber o suficiente sobre a avaliação de crianças aprendendo uma LE. Como discutiremos mais adiante, isso pode vir a ser um problema na atuação desses profissionais haja vista que a avaliação é parte central do processo de ensino e aprendizagem.

Quanto aos contextos nos quais os participantes atuam, estes se mostraram bem diversificados: 29,1\% ensino fundamental público; escola de línguas ficou em segundo lugar (16,6 \%). Ed. Infantil e Ensino Fundamental no setor privado obtiveram a terceira maior porcentagem 12,6\%. Concernente às línguas estrangeiras ensinadas, apenas 3 respondentes afirmaram não ensinar inglês, mas sim espanhol.

Em síntese, os participantes deste estudo eram predominantemente mulheres $(88,1 \%)$ entre 21 e 53 anos, com tempo de experiência profissional bastante variável (entre 6 meses e 30 anos). 75,5\% afirmou atuar no ensino de LEC e 51,5\% considera-se novato nesse contexto de atuação. Embora uma parcela dos participantes tenha informado ser experiente em ensino de LEC (43,7\%), foi possível perceber, por meio das respostas ao questionário, que não possuíam muita informação sobre como trabalhar com avaliação no contexto de ensino de línguas nas séries iniciais.

Fica evidenciado que, conforme apontado na parte introdutória deste artigo, o ensino de LIC e/ou LEC vem ganhando destaque nos dias atuais, e com isso, percebe-se a importância da formação do professor que atua ou deseja atuar nesse âmbito. Prova desse crescimento da área é que, se somarmos a porcentagem daqueles que se consideram novatos àqueles que se veem como experientes no referido campo de ensino, temos um número significativo de docentes que já atuam no ensino de LE nas séries iniciais. Outro dado importante, ainda relacionado ao perfil dos professores respondentes, é que muitos já 
atuam no setor público, o que há alguns anos não seria algo presente em nosso país (TANACA, 2017).

Evidentemente que o fato de o formulário ter sido encaminhado para um público específico, permitiu-nos obter os dados aqui apresentados. Todavia, do nosso ponto de vista, isso não enfraquece nossos argumentos de que a área vem crescendo. Pelo contrário, o simples fato de termos, no Brasil, eventos e cursos acadêmicos voltados especificamente para professores de LE que atuam nas séries iniciais sinaliza, a nosso ver, a urgência de capacitarmos esses profissionais para que possam atuar de maneira segura, com o respaldo teórico-prático que necessitam.

Prosseguimos com as análises das respostas às quatro assertivas selecionadas para serem discutidas neste artigo, apresentando o questionamento e o comando que precediam cada uma das 70 assertivas?

Como professor (a) de línguas para crianças de 0 a 12 anos, o quanto VOCÊ SABE sobre cada um dos aspectos da avaliação de línguas listados abaixo? Por favor utilize a escala a seguir.

A seguinte legenda acompanhava cada uma das afirmações apresentadas e, após a leitura de cada uma delas, os respondentes deveriam assinalar aquela que correspondesse à sua realidade: $\mathbf{0}$ = não sei nada sobre isso; 1 = sei só um pouquinho sobre isso; 2 = sei um pouco sobre isso; 3 = sei bastante sobre isso; 4 = sei muito sobre isso.

\section{Saber utilizar as avaliações para guiar os objetivos do ensino ou da aprendizagem}

A primeira assertiva está relacionada os saberes para utilizar as avaliações para guiar os objetivos do ensino ou da aprendizagem:

Os dados - Gráfico 1 - mostram que do total de 151 respondentes, 2,6\% afirmou não saber nada sobre o assunto; 33,1\% disse saber só um pouquinho sobre o assunto; ${ }^{9}$ Reforçamos que esse total de assertivas refere-se à pesquisa mais ampla desenvolvida pelas autoras e que, para
esse artigo, quatro foram selecionadas. 
41,1\% considera que sabe pouco sobre o assunto; 18,5 acredita saber bastante e 4,6 afirma saber muito sobre o tema.

Gráfico 1: a avaliação e os objetivos do ensino ou da aprendizagem

\section{Como usar as avaliações para guiar os objetivos do ensino ou da} aprendizagem de línguas

151 respostas

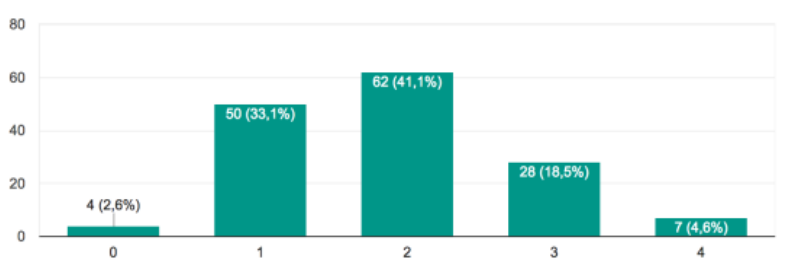

Fonte: as autoras.

Somando aqueles que consideram não saber nada sobre o assunto; saber só um pouquinho e os que acreditam que sabem pouco sobre o assunto, temos o total de $76,80 \%$ dos participantes que desconhecem (total ou parcialmente) quais as possíveis maneiras de utilizar as avaliações para guiar os objetivos do ensino ou da aprendizagem, função essencial de uma avaliação.

Um estudo desenvolvido na Áustria sobre a avaliação da aprendizagem de inglês por alunos do Ensino Primário ${ }^{10}$ (MEWALD e WALLNER, 2015) revelou que grande parte dos países Europeus, oferta o ensino de LE naquela etapa de escolarização. Por isto, em 2012, foi desenvolvido um documento - G4 - contendo as expectativas de aprendizagem para os alunos ao final do ensino primário. Conforme descrito por Mewald e Wallner (2015), o documento oferece um guia para os professores - e também para os pais, os quais

${ }^{10}$ Correspondente ao Primeiro Ciclo do Ensino Fundamental no Brasil (1 ${ }^{\circ}$ ao $9^{\circ}$ ano). 
possuem expectativas altas em relação à aprendizagem dos filhos, para que possam avaliar (ou conhecer) os resultados de aprendizagem apresentados pelos alunos.

Os autores explicam ainda que os descritores contidos no G4 oferecem orientações para a fase de transição do ensino primário para o secundário evitando, assim, que a cada ano o ensino comece "do zero"; o que nas palavras deles, poderia transformar o ensino em algo tedioso e ser um desperdício de tempo e esforço tanto por parte dos professores quanto por parte dos alunos. No entanto, advertem que definir e conhecer o que as crianças podem realizar ao final de cada ano escolar é essencial para, justamente, guiar os próximos passos e objetivos.

\section{Saber utilizar as avaliações para avaliar o progresso na aprendizagem de línguas}

Como evidenciado no gráfico 2, a seguir, um total de $31,8 \%$ dos respondentes diz saber só um pouquinho sobre como utilizar as avaliações para avaliar o progresso na aprendizagem de línguas; enquanto 40,4\% afirma saber um pouco sobre isso. Em sua totalidade, $72,20 \%$ concordam que seus conhecimentos sobre o uso da avaliação para conhecer o quanto o aluno progrediu na aprendizagem de línguas é pouco, o que, de acordo com a literatura especializada (FULCHER, 2012) indica baixo grau de letramento em avaliação dos professores.

Gráfico 2: a avaliação e o progresso na aprendizagem de línguas

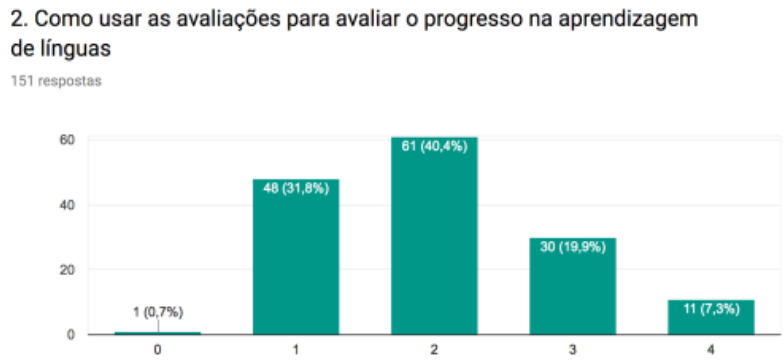

Fonte: as autoras. 
Pautada em Scaramucci (1998/1999), Quevedo-Camargo (2014, p. 246) afirma que,

Para avaliar adequadamente, é preciso ter conhecimentos sobre como proceder, pois, somente um planejamento cuidadoso da avaliação cria condições para que ela possa desempenhar seu papel de mola propulsora da aprendizagem.

Sendo assim, avaliar o progresso na aprendizagem de línguas - incluindo LEC envolve familiarizar-se com algumas noções de conhecimento da língua sendo ensinada e, no caso específico de crianças, demanda também conhecer o que pode ser esperado em termos de desenvolvimento linguístico nas diferentes faixas etárias sem, contudo, esquecer os motivos pelos quais crianças aprendem uma língua estrangeira.

Nesta pesquisa não nos deteremos nas definições sobre proficiência linguística, mas nos concentramos no fato de que, conforme pontuado por Quevedo-Camargo (2014, p. 252), a avaliação da aprendizagem da língua inglesa deve privilegiar a "visão da língua como prática social, o uso e o desempenho".

Importa considerar que, ao tratarmos do ensino de qualquer língua estrangeira, independentemente da faixa etária, é preciso ter em mente que tal atividade precisa significar algo para o aluno. Desse modo, as atividades desenvolvidas em sala de aula devem propiciar momentos nos quais as crianças utilizem a língua estrangeira com um objetivo específico. Dito de maneira mais concreta, isso significa o uso da língua em momentos que demandem do aluno a comunicação com o outro: jogar um jogo, cantar uma canção, (re)contar uma história ou transmitir uma mensagem. O ensino na infância deve possibilitar o engajamento discursivo do aluno em atividades de seu cotidiano, ainda que tal engajamento seja "somente" em sala de aula, nos casos em que a língua não é utilizada no cotidiano do aluno.

Desse modo, é preciso deixar claro que os modos de avaliar possuem relação direta com o conceito que se tem língua e linguagem. Nas palavras de Scaramucci (2006, p. $59)$, 
Considerar, por exemplo, a língua como um sistema integrado, holístico de comunicação e de reflexão, meio e reflexo de uma cultura ou ainda [...] uma ação conjunta entre participantes para fazer algo com um propósito social - uma atividade ao mesmo tempo cognitiva e social - pressupõe uma meta a ser alcançada ou uma noção de proficiência que, nesse caso, envolve o domínio de conhecimentos linguísticos, socioculturais, situacionais e discursivos, mas principalmente, a capacidade de usar, conjuntamente, esses conhecimentos em situações reais de comunicação.

Assim, é preciso que o professor de línguas que atua no contexto investigado considere sua própria visão de língua e linguagem, pois esta influenciará diretamente na escolha dos instrumentos de avaliação e na própria atividade avaliativa em si.

Outro ponto a ser levado em conta quando falamos em avaliar crianças aprendendo línguas são algumas características das crianças que podem influenciar o processo de aprendizagem e, consequentemente, a avaliação. Uma dessas características, conforme Malloy (2015), é o fato de que crianças aprendendo uma LE compreendem mais do que produzem. Por isto o avaliador deve considerar atividades que incluem tarefas de compreensão e produção da língua considerando que o aluno, muitas vezes, compreende o que foi dito, mas não desenvolveu habilidades para produzir respostas - sejam elas escritas ou orais. Desse modo, restringir a natureza das tarefas avaliativas pode produzir um resultado irreal ao professor ou ao avaliador.

\section{Saber utilizar as avaliações para diagnosticar os pontos fortes e fracos dos alunos}

Tsagari e Ioannou-Georgiu (2017) afirmam ser necessário conhecer os aspectos positivos e negativos da avaliação da aprendizagem de LEC uma vez que identificar crianças mais habilidosas ou menos habilidosas não é uma tarefa simples podendo rotulá-las e comprometer a motivação para aprender. Sendo assim, Tsagari e Ioannou-Georgiu (2017, s.p.) afirmam ser necessária uma abordagem crítica de avaliação ao invés de aceitar que qualquer tipo de avaliação é necessariamente apropriado em todos os contextos educacionais. No entender das autoras, "uma abordagem crítica de avaliação pode, por exemplo, fazer com 
que professores de LEC questionem o valor de certas práticas avaliativas comumente aceitas no mundo dos aprendizes adultos”.

Butler (2016), por sua vez, afirma que as características próprias às crianças devem ser consideradas ao decidir, por exemplo, que tipo de instrumento avaliativo será utilizado. A autora acrescenta que é essencial levar em conta os níveis de desenvolvimento cognitivo e social para, então, escolher os instrumentos de avaliação. Outro fator apontado pela autora e que nos interessa nas análises dos dados aqui apresentados é o fato de que, para ela, a avaliação da aprendizagem nesta faixa etária nos leva ao papel importante que o professor possui nesse processo uma vez que os efeitos retroativos (TSAGARI, 2009, 2016) da avaliação devem influenciar os modos de ensinar.

Popham (2009) defende que as avaliações realizadas em sala de aula referem-se àqueles procedimentos formais e informais realizados utilizados por professores com vistas a fazer inferências precisas sobre o que os alunos sabem (em termos de conhecimento de língua) e o que conseguem realizar a partir daquele conhecimento.

Gráfico $3^{11}$ : a avaliação no diagnóstico de pontos fortes e fracos dos alunos

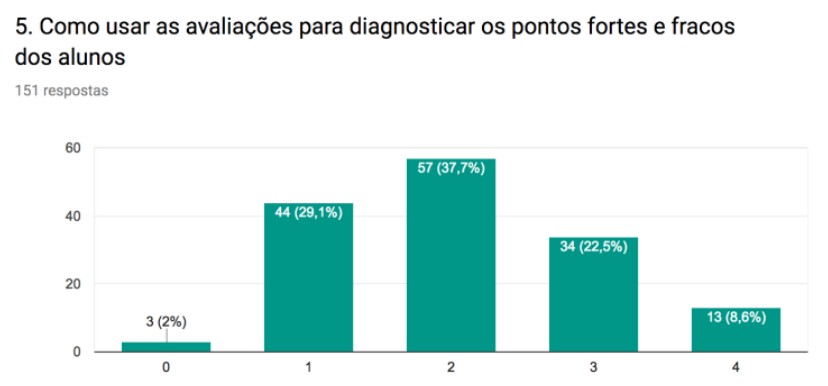

Fonte: as autoras.

\footnotetext{
${ }^{11}$ Por tratar-se de um recorte de uma pesquisa maior, os números dos gráficos nesse artigo nem sempre correspondem aos números dos gráficos no original.
} 


\section{Saber utilizar as avaliações para motivar a aprendizagem dos alunos}

Por muito tempo a literatura especializada tomou a aprendizagem de LEC como sinônimo de sucesso levando em consideração o fator "idade", isoladamente. Tal quadro apoiou-se em pesquisas advindas da Hipótese de Período Crítico (ELLIS, 1994) a qual preconizava, resumidamente, haver uma fase da vida na qual o aprendiz, ao ser exposto à uma LE, a aprenderia de forma "natural" assim como acontece com a língua primeira e que esta fase seria a infância. Atualmente, contudo, sabe-se que o fator "idade" por si só não garante a aprendizagem de uma LE (PIRES, 2001). Todavia, um dos resultados de estudos que defendiam que as crianças, em comparação aos adultos, aprendem melhor uma LE seria a motivação natural para a aprendizagem. Ou seja, pelo fato de "ser criança", este aprendiz seria "naturalmente" motivado ou aberto à aprendizagem.

No entanto, pesquisas mais recentes nos mostram que a motivação - além da elaboração de um currículo adequado, da formação do professor e do monitoramento do progresso da aprendizagem (CAMERON, 2001; SINGLETON, 2014; NIKOLOV, 2016) - é justamente um dos desafios no percurso do ensino e aprendizagem de LEC. Para Nikolov (2016), quanto mais cedo a LE é introduzida na escola, mais rápido as atividades podem tornarem-se entediantes desafiando assim, a manutenção da motivação da criança para aprender uma LE, o que contraria a ideia de que ensinar crianças é uma atividade simples uma vez que, teoricamente, elas seriam naturalmente interessadas por tudo.

A esse respeito, alguns autores (MCKAY, 2006; PINTER, 2006; RIXON, 2007; 2016, por exemplo) tomam o ato de avaliar como uma possibilidade de mostrar para o aluno seu progresso no processo de aprendizagem e, assim, motivá-lo a continuar aprendendo, cumprindo assim o seu papel formativo. Nikolov (2016), apoiada em Prabhu (2009), nos lembra que a aprendizagem LE nos anos iniciais de escolarização visa, principalmente, contribuir com atitudes positivas do aprendiz em relação à aprendizagem daquela LE, aos próprios falantes de outras línguas, e em relação à sua própria cultura e identidade. Ainda sobre a motivação, um estudo desenvolvido por Nikolov (2016) mostra que há uma relação importante entre a identidade de crianças aprendizes de LE e a avaliação. A autora mostra 
que ao longo do processo de aprendizagem, as acrianças se revelam ansiosas e, com o passar do tempo, tendem a perder a motivação para a aprendizagem.

McKay (2006) indica algumas características que distinguem crianças de outras faixas etárias de aprendizes. Uma delas é que as crianças são vulneráveis à falhas e críticas e, por isto, necessitam de atenção especial. A esse respeito, nos parece razoável afirmar que a avaliação assume um papel que é, ao mesmo tempo, importante e delicado, pois caso o instrumento não seja adequado ou o feedback não seja fornecido (ou seja feito de maneira a não fazer sentido para a criança), a avaliação em si e os resultados decorrentes a ela podem comprometer e desestimular o aluno. Por outro lado, acreditamos ser perfeitamente possível que a avaliação seja utilizada com vistas a promover e motivar a aprendizagem. Por isto, reforçamos ser necessário que a formação de professores aborde a avaliação da aprendizagem de LEC para que os docentes sejam letrados nessa temática o que, a partir dos dados gerados, não nos parece ser a realidade brasileira, conforme gráfico 4 , a seguir.

Gráfico 4: a avaliação na motivação da aprendizagem

6. Como utilizar as avaliações para motivar a aprendizagem dos alunos

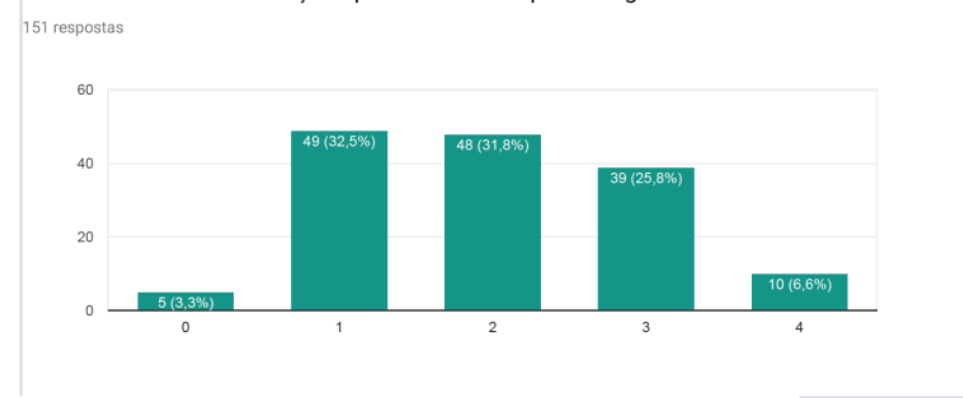

Fonte: as autoras.

A partir do gráfico 4, nota-se que os dados quantitativos revelam, mais uma vez, que a grande concentração das respostas (64,3\%) ficou entre os índices 1 e 2 (aqueles que afirmaram saber só um pouquinho sobre isso e saber um pouco sobre isso). Já os que 
consideram saber bastante e saber muito sobre isso (alternativas 3 e 4, respectivamente) somam $32,4 \%$.

Como pontuado anteriormente, seria interessante conhecer o que os respondentes realizam, de fato, em termos de avaliação em suas práticas de sala de aula e quais procedimentos são por eles utilizados para motivar a aprendizagem dos alunos a partir dos resultados obtidos nas avaliações. A nosso ver, a partir de tais práticas de sala de aula poderíamos compreender melhor os motivos que levaram os respondentes a afirmarem que sabem o que sabem nas respostas obtidas.

Após a análise dos dados obtidos, depreendemos, de modo geral que os saberes escolhidos para a presente discussão indicam aspectos importantes para as questões relacionadas ao ensino e à aprendizagem de LIC e/ou LEC.

No que se refere a utilizar a avaliação para atingir os objetivos de ensino, percebese que tal ponto é essencial para inclusive, traçar e atingir expectativas de aprendizagem. $76,80 \%$ dos participantes afirmaram desconhecer (total ou parcialmente) as possíveis maneiras de utilizar as avaliações para guiar os objetivos do ensino ou da aprendizagem. Ou seja, um dos pontos centrais do processo avaliativo não é conhecido pelos participantes.

Ao falarmos da aprendizagem de línguas, é preciso ter em mente, em consonância com os teóricos da área, que a avaliação precisa ter um olhar diferenciado, pois não se trata de avaliar a aprendizagem em geral, mas sim de (re)conhecer no aluno o quanto ele se desenvolveu ou não em termos de conhecimento e uso da língua. A partir disso, entendemos que, valer-se da avaliação para diagnosticar os pontos fortes e fracos dos alunos, o professor pode traçar estratégias e incluir em seu planejamento diário atividades que cooperem para atingir o objetivo central de sua atividade que é fazer com que a turma - ou até mesmo um só aluno - reconheça o que já consegue fazer e o que precisa ser melhorado.

Ancoradas no referencial teórico que sustenta esta pesquisa, afirmamos ser este um aspecto importante ao falarmos de avaliação da aprendizagem de línguas por crianças, pois ao conhecer os pontos fortes e fracos de seus alunos, o professor pode redimensionar suas 
práticas de sala de aula e, se for o caso, (re)adaptá-las para que o desenvolvimento linguístico dos alunos ocorra.

Por fim, mas não menos importante, nossas análises revelam que muitos professores desconhecem ou dizem desconhecer como valer-se dos resultados dos processos avaliativos para motivar a aprendizagem de LEC.

A seguir, nossas reflexões finais.

\section{Reflexões finais}

O objetivo deste artigo foi apresentar um recorte de uma pesquisa mais ampla a qual foi desenvolvida com 151 professores de inglês e espanhol a respeito de conhecimentos sobre avaliar línguas estrangeiras nas séries iniciais. A partir das 70 assertivas que compunham a pesquisa original, selecionamos quatro que consideramos cruciais, e que se constituem em saberes essenciais para que o professor desenvolva seu trabalho integrando ensino-aprendizagem-avaliação. A primeira assertiva referia-se a saber utilizar avaliações para guiar os objetivos do ensino ou da aprendizagem. Esse saber é extremamente necessário, pois significa saber valer-se dos instrumentos avaliativos para caminhar no sentido de atingir os objetivos estabelecidos no planejamento, ao mesmo tempo em que leva em consideração as informações obtidas dos alunos no processo de aprendizagem para reavaliação, e redirecionamento quando necessário, dos objetivos almejados.

A segunda assertiva relacionava-se a saber utilizar as avaliações para avaliar o progresso na aprendizagem de línguas. Este seria, em princípio, um saber básico para qualquer professor, pois constitui-se na função primordial da avaliação. Afinal, é para isso que avaliamos: para verificar se os alunos estão evoluindo na aprendizagem.

Em seguida, a terceira assertiva versava sobre saber utilizar as avaliações para diagnosticar os pontos fortes e fracos dos alunos. Aqui, novamente, trata-se de um saber extremamente importante que se refere à conhecida função diagnóstica da avaliação. Por meio dela, a avaliação retroalimenta o processo de ensino e de aprendizagem ao possibilitar 
ao professor que identifique objetivos que já foram atingidos e quais ainda devem ser mais bem trabalhados em classe ou com alunos específicos.

Por fim, a quarta e última assertiva que selecionamos era sobre saber utilizar as avaliações para motivar a aprendizagem dos alunos. Este, na nossa visão, é um saber crucial especialmente no contexto de ensino de LEC, pois refere-se tanto a ensinar a celebrar as conquistas e os objetivos atingidos no processo de aprendizagem de línguas quanto a ensinar a não desistir ou desanimar diante de obstáculos ou dificuldades.

Reconhecemos que colocar esses quatro saberes essenciais em prática não é tarefa fácil, mas acreditamos no poder transformador da avaliação com mola propulsora (SCARAMUCCI, 2006) do processo de ensino e aprendizagem de línguas estrangeiras, em especial na infância.

\title{
ESSENTIAL TEACHER KNOWLEDGE FOR THE ASSESSMENT OF CHILDREN'S FOREIGN LANGUAGE LEARNING
}

\begin{abstract}
In the last few decades, there has been significant growth in the teaching of foreign languages to children in Brazil, particularly the English language. Considering learning assessment as a crucial element in teaching and learning, in this article we discuss teacher's assessment literacy in this educational field. The data was generated by means of an online questionnaire, which was answered by 151 teachers from all over the country. The original questionnaire consisted in 70 statements about a wide variety of issues related to the assessment of children learning foreign languages. For the purpose of this article, aiming at presenting part of a broader research on assessment literacy, we selected four statements which, from our point of view, are crucial knowledge to teachers' work and to the integration of teaching, learning and assessment: to know how to use assessment to guide teaching and learning objectives; to know how to use assessment to verify students' learning progress; to know how to use assessment to diagnose students' strengths and weaknesses; and to know how to use assessment to motivate students' learning.

The results showed that the great majority of the participants consider they either do not know or know little about these four issues, which indicates the urgent need of offering initial and ongoing education to those teaching foreign languages to children in Brazil.
\end{abstract}

KEYWORDS: Essential teachers' knowledge; Language assessment literacy; Teaching foreign languages to children. 


\section{REFERÊNCIAS}

ANDRADE, Maria Eugênia Sebba Ferreira; CONCEIÇÃO, Mariney Pereira. Letramento em língua estrangeira no Ensino Fundamental: ampliando o exercício de cidadania das crianças brasileiras. In: TONELLI, Juliana Reichert Assunção; PÁDUA, Lívia de Souza; OLIVEIRA, Thays Regina Ribeiro (Org.). Ensino e formação de professores de linguas estrangeiras para crianças no Brasil. Curitiba/PR: APPRIS, 2017. p. 121- 149.

ANDRADE, Bárbara. Avaliação na produção oral de língua estrangeira para crianças: uma proposta de acompanhamento do processo de aprendizagem. 2016. $58 \mathrm{f}$. Trabalho (Mestrado Profissional em Letras Estrangeiras Modernas) - Universidade Estadual de Londrina, Londrina, 2016.

BUOSE, Vera Lúcia de Oliveira Pereira; SANTOS, Leandra Inês Seganfredo. Oficina de língua inglesa para criança: uma sequência didática com gênero textual em ação. In: TONELLI, Juliana Reichert Assunção; PÁDUA, Lívia de Sousa; OLIVEIRA, Thays Regina Ribeiro de Oliveira. Ensino e formação de professores de linguas estrangeiras para crianças no Brasil. Curitiba/PR: APPRIS, 2017. p. $95-120$.

BUTLER, Yuko Goto. Self-assessment of and for young learners' foreign language learning. In: Nikolov, Marianne. (Ed.). Assessing young learners of English: Global and local perspectives. New York: Springer, 2016.

CAMERON, Lynne. Teaching languages to young learners. Cambridge: Cambridge University Press, 2001.

COLOMBO, Camila Sthéfanie; CONSOLO, Douglas Alatamiro. 2017. Ensino de inglês como língua estrangeira para crianças: a qualidade do insumo oral. In: TONELLI, Juliana Reichert Assunção; PÁDUA, Lívia de Souza; OLIVEIRA, Thays Regina Ribeiro de. Ensino e formação de professores de línguas estrangeiras para crianças no Brasil. Curitiba/PR: APPRIS, 2017. p. $207-224$.

COOMBE, Christine; DAVIDSON, Peter; O'SULLIVAN, Barry; STOYNOFF, Stephen. (Eds). The Cambridge guide to second language assessment. Cambridge: Cambridge University Press, 2012.

COSTA, Leny Pereira. Uso de um exame internacional de proficiência em lingua inglesa para crianças no ensino fundamental brasileiro. 2008. 144 f. Dissertação (Mestrado em Linguística Aplicada) - Universidade Estadual de Campinas, Campinas, 2008.

DIAS, Jeovana Karla Oliveira; BROSSI, Giuliana Castro. 2015. Reflexões e inquietações acerca do ensino de língua inglesa nos anos iniciais. Pesquisas em Discurso Pedagógico (online), Rio de Janeiro/RJ, v. 1, p. 1-26. Disponível em: https://www.maxwell.vrac.pucrio.br/24802/24802.PDFXXvmi= . Acesso em: 10 mai. 2019.

ELLIS, Rod. The study of second language acquisition. Oxford: Oxford University Press, 1994. 
FULCHER, Glenn. Assessment literacy for the language classroom. Language Assessment Quarterly, v. 2. n.9. p. $113-132.2012$.

GORDON, Tatiana. Teaching young children a second language. Westport, CT: PRAEGER Publishers, 2007. 233 p.

HASSELGREEN, Angela. Assessing young learners. In: COOMBE, C.; DAVIDSON, P.; O'SULLIVAN, B.; STOYNOFF, S. (Eds). The Cambridge guide to second language assessment. Cambridge: Cambridge University Press, 2012, p. 171-177.

MALLOY, Amy. Seven essential considerations for assessing young learners. Modern English teachers, v. 24, n. 1, p. 20-23, 2015.

McKAY, Penny. Assessing young language learners. Cambridge University Press, 2006.

MEWALD, Claudia; WALLNER, Sabine. Assessing young foreign language learners: when assessment serves learning. Open Online Journal for Research and Education. Abril, 2015. Disponível em https://journal.ph-noe.ac.at/index.php/resource/article/view/184 . Acesso em 10 de outubro de 2018.

LEMES, Flaviane Montes Miranda. Formação crítica docente e seu reflexo no ensino crítico de inglês para crianças: experiências transformadoras. In: TONELLI, Juliana Reichert Assunção; PÁDUA, Lívia de Souza; OLIVEIRA, Thays Regina Ribeiro. Ensino e formação de professores de linguas estrangeiras para crianças no Brasil. Curitiba/PR: APPRIS, 2017. p. 151175.

MOSQUERA, Leonardo Herrera; MACÍAS, Diogo Fernando. A call for language assessment literacy in the education and development of teachers of English as a foreign language. Colomb. Appl. Linguist. J., v. 17. n.2. p. 302-312. 2015.

NIKOLOV, Marianne. (Ed.) Assessing Young Learners of English: Global and Local Perspectives. Cham: Switzerland, Springer International Publisher, 2016.

OLIVEIRA, Marcia Elaine. “Alguém como nós”: uma iniciativa de reorganização do contexto de ensino de inglês para crianças no município de Londrina. 2016. 95 f. Trabalho de conclusão de curso (Mestrado Profissional em Letras Estrangeira Modernas) - Universidade Estadual de Londrina, Londrina, 2016.

OLIVEIRA, Jordanah Schroder Fortes. Avaliação em um curso de lingua estrangeira para crianças no Ensino Fundamental 1: uma professora em busca de subsídios para sua prática. 2018. 148 f. Dissertação (Mestrado em Linguística Aplicada) - Universidade de Brasília, Brasília, 2018.

PÁDUA, Lívia Souza. O portfólio como instrumento avaliativo no ensino-aprendizagem de língua inglesa para crianças. 2016. 56 f. Trabalho (Mestrado Profissional em Letras Estrangeiras Modernas) - Universidade Estadual de Londrina, Londrina, 2016.

PINTER, Annamaria. Teaching young language learners. Oxford: Oxford University Press, 2006. 
PIRES, Simone Silva. Vantagens e desvantagens do ensino de língua estrangeira na educação infantil: um estudo de caso. 2001. 131 f. Dissertação (Mestrado em Linguística Aplicada) - Universidade Federal do Rio Grande do Sul, Porto Alegre, 2001.

POPHAM, W. James. Why assessment literacy is professional suicide. Educational Leadership, v. 62, n. 1. p. 82-83. 2004.

POPHAM, W. James. Assessment literacy for teachers: faddish or fundamental? Theory into Practice, v. 48. n. 1. p. 4 -11. 2009.

PRABHU, N. S. Teaching English to young learners: the promise and the threat. In J. Enever, J. Moon; U. Raman (Eds.). Young learner English language policy and implementation: international perspectives. Reading, UK: Garnet Education Publishing, 2009. p. 43-44.

QUEVEDO-CAMARGO, Gladys. Proficiência linguística e avaliação da produção oral em língua inglesa. In: EL-KADRI, M.S.; PASSONI T.P.; GAMERO, R. (Orgs.) Tendências contemporâneas para o ensino de lingua inglesa: propostas didáticas para a educação básica. Campinas: Pontes Editores, 2014. p. 245-272.

. Letramento em avaliação do professor de linguas: componentes e lacunas. Relatório Final de Estágio Pós-Doutoral, Programa de Pós-Graduação em Linguística Aplicada. Universidade Estadual de Campinas, Campinas, 2018. Mimeo.

QUEVEDO-CAMARGO, Gladys.; SCARAMUCCI, Matilde Ricardi. O conceito de letramento em avaliação de línguas: origem de relevância para o contexto brasileiro. LING. Est. e Pesq., Catalão-GO, v. 22. n. 1. jan. /jun. p. 225-245. 2018.

RIXON, Shelagh. Cambridge ESOL YLE tests and children's first steps in reading and writing in English. Cambridge ESOL Research Notes. n. 28. p. 7-14. 2007.

. Do Developments in Assessment Represent the 'Coming of Age' of Young Learners English Language Teaching Initiatives? The International Picture. In NIKOLOV, Marianne (Ed.) Assessing Young Learners of English: Global and Local Perspectives. Cham: Switzerland, Springer International Publisher, 2016. p. 19-42.

ROCHA, Cláudia Hilsdorf; BASSO, Edcleia Aparecida. (Orgs.). 2007. Ensinar e aprender lingua estrangeira nas diferentes idades: reflexões para professores e formadores. São Carlos/SP: Claraluz.

SANTOS, Leandra Inês Seganfredo. 2005. Crenças acerca da inclusão de lingua inglesa nas séries iniciais: quanto antes melhor? 230f. Dissertação (Mestrado em Estudos Linguísticos) - Instituto de Linguagem, Universidade Federal do Mato Grosso, Cuiabá/MT, 2005.

. 2009. Lingua Inglesa em anos iniciais do Ensino Fundamental: fazerer pedagógico e formação docente. 274 f. Tese (Doutorado em Estudos Linguísticos) - Universidade Estadual Paulista "Júlio de Mesquita Filho", São José do Rio Preto/SP, 2009. 
SCARAMUCCI, Matilde Ricardi. O professor avaliador: sobre a importância da avaliação na formação do professor de língua estrangeira. In: ROTTAVA, L.; SANTOS, S. S. (Org.) Ensino-aprendizagem de línguas: língua estrangeira. Ijuí: Editora da UNIJUI, 2006. p. 4964.

- Avaliação da leitura em inglês como língua estrangeira e validade de construto. Calidoscópio, v. 7, n. 1, p. 30-48, jan. / abr. 2009.

SELBACH, Helena Vitalina; SARMENTO, Simone. The crazy car story: um projeto em língua inglesa na Educação Infantil. In: TONELLI, Juliana Reichert Assunção; PÁDUA, Lívia de Souza; OLIVEIRA, Thays Regina Ribeiro. Ensino e formação de professores de línguas estrangeiras para crianças no Brasil. Curitiba/PR: APPRIS, 2017. p. 273- 310.

SINGLETON, David. Apt to change: the problematic of language awareness and language aptitude in age-related research. Studies in Second Language Learning and Teaching, 2014.

STIGGINS, Rick. Assessment Literacy. The Phi Delta Kappan, v. 72, n.7, p. 534-539. 1991. 245. 1995. . Assessment Literacy for the 21 st Century. The Phi Delta Kappan, v. 77, n. 3, p. 238-

. Assessment crisis: the absence of assessment for learning. The Phi Delta Kappan, v. 83 , n. 10 , p. 758-765. 2002.

TANACA, Jozélia Jane. 2017. Aprendizagem expansiva em espaços hibridos de formação continuada de professoras de inglês para crianças no Projeto Londrina Global. 257 f. Tese (Doutorado em Estudos da Linguagem) - Universidade Estadual de Londrina, Londrina/PR.

TOFFOLI, Sônia Ferreira Lopes; ANDRADE, Dalton Francisco de; BORNIA, Aantonio Cezar; QUEVEDO-CAMARGO, Gladys. Avaliação com itens abertos: validade, confiabilidade, comparabilidade e justiça. Educ. Pesquisa, São Paulo, v. 42, n. 2, p. 343-358, abr./jun. 2016.

TONELLI, Juliana Reichert Assunção. 2005. Histórias infantis no ensino da língua inglesa para crianças. 312 f. Dissertação (Mestrado em Estudos da Linguagem) - Universidade Estadual de Londrina, Londrina/PR, 2005.

; QUEVEDO-CAMARGO, Gladys. Teaching EFL to children: reflections on (future) teachers' language assessment literacy. Revista Horizontes de Linguística Aplicada, v. 17, p. 63-91. 2018.

; PÁDUA, Lívia de Souza. O estado da arte de pesquisas sobre ensino e formação de professores de línguas estrangeiras para crianças no Brasil. In: TONELLI, Juliana Reichert Assunção; PÁDUA, Lívia de Souza; OLIVEIRA, Thays Regina Ribeiro. Ensino e formação de professores de línguas estrangeiras para crianças no Brasil. Curitiba/PR: APPRIS, 2017. p. 17-39. 
. Contextos (in)explorados no estágio supervisionado nas licenciaturas em letras/inglês: o lugar da observação de aulas nos dizeres de alunos-mestres. Signum: Estudos da Linguagem, Londrina/PR, v. 19, n. 2, p. 35-65, 2016.

; CRISTOVÃO, Vera Lúcia Lopes. O papel dos cursos de Letras na formação de professores de inglês para crianças. Calidoscópio, São Leopoldo/RS, v. 8, n. 1, p. 65-76. 2010.

; FERREIRA, Otto Henrique; BELO-CORDEIRO, Areta Estefane. Remendo novo em vestido velho: uma reflexão sobre os cursos de letras-inglês. REVELLI - Revista de Educação, Lingua e Literatura, Inhumas/GO, v. 9. p. 124-141. 2017.

TSAGARI, Dina. The Complexity of Test Wasbback: An Empirical Study. Frankfurt am Main: Peter Lang GmbH, v. 15, n. 1, 2009.

- Assessment Orientations of State Primary EFL Teachers in Two Mediterranean Countries. C.E.P.S Journal, v. 6. n 1. 2016.

; IOANNOU-GEORGIU, Sophie. Assessing English Competences of Young Learners in Primary School Education. In: CAPPERUCCI, D.; GUERIN, E. Innovative European Approaches for In-service and Pre-service English Language Teachers in Primary Education: Theory and Practice. Bologna: EDIZIONI ETS, 2017, p. 237.

TUTIDA, Alessandra Ferraz. 2016. Ensino de lingua inglesa para crianças: questões sobre formação de professores e os saberes da prática. $314 \mathrm{f}$. Dissertação (Mestrado em Estudos da Linguagem) - Universidade Estadual de Londrina, Londrina-PR, 2016.

Recebido em: 30/05/2019.

Aprovado em: 30/07/2019. 